\title{
Is experience with extracorporeal urinary diversion following robotic assisted radical cystectomy necessary before transitioning to intracorporeal urinary diversion?
}

\author{
Wei Shen Tan ${ }^{1,2}$, John D. Kelly ${ }^{1,2}$ \\ ${ }^{1}$ Division of Surgery \& Interventional Science, University College London, London, UK; ${ }^{2}$ Department of Urology, University College London \\ Hospital, London, UK \\ Correspondence to: Wei Shen Tan. Division of Surgery \& Interventional Science, University College London, 3rd floor Charles Bell House, \\ 43-45 Foley Street, London W1W 7TS, UK. Email: wei.tan@ucl.ac.uk. \\ Provenance: This is an invited Editorial commissioned by Section Editor Xiao Li (Department of Urology, Jiangsu Cancer Hospital \& Jiangsu \\ Institute of Cancer Research \& Nanjing Medical University Affiliated Cancer Hospital, Nanjing, China). \\ Comment on: Tan TW, Nair R, Saad S, et al. Safe transition from extracorporeal to intracorporeal urinary diversion following robot-assisted \\ cystectomy: a recipe for reducing operative time, blood loss and complication rates. World J Urol 2018:1-6.
}

Submitted Aug 09, 2018. Accepted for publication Aug 14, 2018.

doi: $10.21037 /$ tau.2018.08.22

View this article at: http://dx.doi.org/10.21037/tau.2018.08.22

Efforts to minimise the high morbidity following open radical cystectomy have led to the development of robotic assisted radical cystectomy (RARC) (1). Since first reported in 2003, the uptake of RARC has increased in recent years despite the lack of solid evidence to suggest a perioperative benefit $(2,3)$. The recently published RAZOR study which randomised patients to open cystectomy or RARC with extracorporeal urinary diversion (eRARC) reported that 90 days complications rates between the two treatment arms were comparable and while hospital length of stay (LOS) was lower favouring the RARC arm (6 vs. 7 days, $\mathrm{P}=0.02$ ), this is not clinically meaningful (4). Reassuringly, 2-year progression free survival for the two treatment arms were similar (4).

In the recent issue of World $\mathcal{f}$ Urol, Tan et al. report their experience of transitioning from eRARC to RARC with intracorporeal urinary diversion (iRARC) in their robotic cystectomy programme (5). While they commenced their RARC programme in 2004, they started performing iRARC in October 2016. In their study which analysed patients treated between April 2015 to October 2017, a total of 127 RARC with ileal conduit (68 eRARC and 59 iRARC) were performed. They report that iRARC treated patients had a significantly lower operating time $(330 \mathrm{vs} .375 \mathrm{~min}$, $\mathrm{P}=0.019$ ), lower blood loss ( 300 vs. $425 \mathrm{~mL}, \mathrm{P}>0.035$ ), and lower 30 -day overall complications (48.4\% vs. $71.4 \%$,
$\mathrm{P}=0.008)$ compared to eRARC. Subsequently, their operating time continued to improve when comparing their first 29 cases to next 30 cases ( $300 v s .360 \mathrm{~min}, \mathrm{P}=0.004$ ).

We congratulate Tan et al. for their study which suggests that iRARC can be safely performed and a transition from eRARC can be done without any subsequent increase in patient morbidity and mortality (5). We note that they have diligently collected 90 -day complications data which are higher than other reported series (6). We acknowledge that reported case series often suffers from retrospective and publication bias. Indeed, in our early experience, we reported a similar 90-day major complication rate $(20.9 \%)$ but lower overall complication rate $(71.7 \%)(7,8)$. Using randomised data as a bench mark, the RARC arm of RAZOR report an overall complication rate of $69 \%$ and a major complication rate of $22 \%$ at 90 days (4).

The results of Tan et al. suggest that their institution may still be in their learning curve given the increase of overall and major complications from $64 \%$ to $79 \%$ and $17 \%$ to $30 \%$ between their two iRARC cohorts (5). While there are no reports suggesting the number of cases required to overcome the learning curve, the Pasadena consensus suggest that a minimum of 100 cases are required before one is considered a very experienced surgeon (9).

We question the requirement for a step wise transition from eRARC to iRARC in contemporary practice. We 
appreciate the cautious approach adopted by the authors and that most robotic cystectomy historically may feel more comfortable with a step wise approach where eRARC is performed before iRARC is attempted. However, at our institution, we made the transition from open cystectomy directly to iRARC. Subsequently, six of our trainees have gone through our programme and can now successfully perform RARC with intracorporeal ileal conduit diversion without previous eRARC experience. We believe the combination of robotic simulators and good mentorship has made this possible. Future trainees are likely to naturally make the transition without the need for eRARC experience.

Nevertheless, we share the same view that iRARC may be beneficial compared to eRARC despite limited evidence $(10,11)$. Reports of early oncological outcomes between open cystectomy and iRARC suggest they are comparable (12). It is worth pointing out that randomised data from RAZOR was comparing open cystectomy to eRARC (4). Many have argued the logic of using a minimal invasive approach to perform the cystectomy only to convert to a laparotomy to perform urinary diversion $(6,13)$. We believe minimising the need of the laparotomy incision will minimise the need for opiate based analgesia which contributes to ileus, the main reason for prolonged hospital LOS (8). Other advantages include lower blood loss due to pneumoperitoneum, loss of insensible fluid and reduced bowel handling. In addition, although unproven, an intracorporeal urinary diversion may reduce uretero-ileal stricture rates by reducing tension during suturing and allowing to use of shorter ureter length minimising the risk of devascularization the distal ureter.

However, an added benefit from iRARC is the ability to draw from the benefits from an enhance recovery after surgery (ERAS) programme to truly maximise perioperative benefits (14). We have shown that early mobilisation and reduced opiate used which is enabled by iRARC allows for reduction in both hospital LOS and complication rate without increasing readmission rates $(14,15)$. We believe, ERAS itself maybe more advantageous compared to a minimal invasive approach but in combination, they may be synergistic.

While iRARC may be advantageous, centralisation of services remains crucial in improving outcomes following radical cystectomy. There is a clear volume relationship with cystectomy outcomes and may explain the disparity of care as well as variation in cost associated with radical cystectomy (16-18). Efforts towards centralisation of services should be encouraged and evidence suggest that 'failure to rescue' rates are lower in high volume centers following complex surgery (19).

In summary, the study by Tan et al. should give confidence to other programmes still performing eRARC to transition to iRARC (1). The publication of the RAZOR trial which does not show a clear benefit for eRARC over open cystectomy should encourage institutions to perform iRARC. While we acknowledge that data supporting the use of iRARC is limited, and our institution is leading a phase III prospective multi-center randomised study comparing open cystectomy to iRARC (iROC trial, ClinicalTrials.gov: NCT03049410) which would hopefully provide evidence on perioperative outcomes comparing iRARC to open cystectomy.

\section{Acknowledgements}

None.

\section{Footnote}

Conflicts of Interest: JD Kelly is a Co-chief investigator for the iROC trial. WS Tan has no conflicts of interest to declare.

\section{References}

1. Tan WS, Lamb BW, Kelly JD. Complications of radical cystectomy and orthotopic reconstruction. Adv Urol 2015;2015:323157.

2. Menon M, Hemal A, Tewari A, et al. Nerve-sparing robotassisted radical cystoprostatectomy and urinary diversion. BJU Int 2003;92:232-6.

3. Tan WS, Khetrapal P, Tan WP, et al. Robotic assisted radical cystectomy with extracorporeal urinary diversion does not show a benefit over open radical cystectomy: a systematic review and meta-analysis of randomised controlled trials. PLoS One 2016;11:e0166221.

4. Parekh DJ, Reis IM, Castle EP, et al. Robot-assisted radical cystectomy versus open radical cystectomy in patients with bladder cancer (RAZOR): an open-label, randomised, phase 3, non-inferiority trial. Lancet 2018;391:2525-36.

5. Tan TW, Nair R, Saad S, et al. Safe transition from extracorporeal to intracorporeal urinary diversion following robot-assisted cystectomy: a recipe for reducing operative time, blood loss and complication rates. World J Urol 2018:1-6.

6. Ahmed K, Khan SA, Hayn MH, et al. Analysis of 
intracorporeal compared with extracorporeal urinary diversion after robot-assisted radical cystectomy: results from the International Robotic Cystectomy Consortium. Eur Urol 2014;65:340-7.

7. Tan WS, Sridhar A, Goldstraw M, et al. Robot-assisted intracorporeal pyramid neobladder. BJU international 2015;116:771-9.

8. Tan WS, Lamb BW, Tan MY, et al. In-depth critical analysis of complications following robot-assisted radical cystectomy with intracorporeal urinary diversion. Eur Urol Focus 2017;3:273-9.

9. Wilson TG, Guru K, Rosen RC, et al. Best practices in robot-assisted radical cystectomy and urinary reconstruction: recommendations of the Pasadena Consensus Panel. Eur Urol 2015;67:363-75.

10. Tan WS, Lamb BW, Khetrapal P, et al. Blood transfusion requirement and not preoperative anemia are associated with perioperative complications following intracorporeal robotassisted radical cystectomy. J Endourol 2017;31:141-8.

11. Lamb BW, Tan WS, Eneje P, et al. Benefits of robotic cystectomy with intracorporeal diversion for patients with low cardiorespiratory fitness: A prospective cohort study. Urol Oncol 2016;34:417.e17-23.

12. Tan WS, Sridhar A, Ellis G, et al. Analysis of open and intracorporeal robotic assisted radical cystectomy shows no significant difference in recurrence patterns and oncological outcomes. Urol Oncol 2016;34:257.e1-9.

Cite this article as: Tan WS, Kelly JD. Is experience with extracorporeal urinary diversion following robotic assisted radical cystectomy necessary before transitioning to intracorporeal urinary diversion? Transl Androl Urol 2018;7(Suppl 6):S735-S737. doi: 10.21037/tau.2018.08.22
13. Desai MM, Gill IS. "The devil is in the details": randomized trial of robotic versus open radical cystectomy. Eur Urol 2015;67:1053-5.

14. Tan WS, Tan MY, Lamb BW, et al. Intracorporeal robotassisted radical cystectomy, together with an enhanced recovery programme, improves postoperative outcomes by aggregating marginal gains. BJU Int 2018;121:632-9.

15. Tan WS, Lamb BW, Sridhar A, et al. A comprehensive guide to perioperative management and operative technique for robotic cystectomy with intracorporeal urinary diversion. Urologia J 2017;84:71-8.

16. Goossens-Laan CA, Gooiker GA, van Gijn W, et al. A systematic review and meta-analysis of the relationship between hospital/surgeon volume and outcome for radical cystectomy: an update for the ongoing debate. Eur Urol 2011;59:775-83.

17. Khetrapal P, Tan WS, Kelly JD. Factors Affecting the Cost of Radical Cystectomy in the USA: Some Centres Are More Equal than Others. Eur Urol 2017;73:383-4.

18. Leow JJ, Cole AP, Seisen T, et al. Variations in the costs of radical cystectomy for bladder cancer in the USA. Eur Urol 2017;73:374-82.

19. Gonzalez AA, Dimick JB, Birkmeyer JD, et al. Understanding the volume-outcome effect in cardiovascular surgery: the role of failure to rescue. JAMA Surg 2014;149:119-23. 